\title{
Exigência de Lisina para Machos Castrados de Dois Grupos Genéticos de Suínos na Fase de Terminação, com Base no Conceito de Proteína Ideal ${ }^{1}$
}

\section{Ivan Moreira², Luiz Fernando Gasparotto ${ }^{3}$, Antônio Cláudio Furlan², Valquíria Mayumi Ishida Patrício $^{4}$, Gisele Cristina de Oliveira ${ }^{4}$}

\begin{abstract}
RESUMO - Foi conduzido um experimento para determinar as exigências de lisina de machos castrados, em fase de terminação, de dois grupos genéticos de suínos, com base no conceito de proteína ideal. Foram utilizados 16 suínos do grupo genético comum (GGC) e 16 suínos do grupo genético melhorado (GGM), distribuídos em quatro tratamentos que consistiram de uma ração basal, à base de milho e farelo de soja, contendo $0,60 \%$ de lisina e outras três rações, acrescentando-se níveis crescentes de lisina para se obter $0,75,0,90$ e $1,05 \%$ de lisina total na ração. Adicionaram-se aminoácidos sintéticos (L-Lisina HCl, DL-metionina, L-treonina e L-triptofano), para manter os níveis de aminoácidos, de acordo com o perfil de proteína ideal. Foi feita a determinação das concentrações de nitrogênio da uréia plasmática (NUP). Fez-se a medição de características de carcaça in vivo, utilizando um aparelho de ultra-som Sono Grader e, ao final do período experimental, 12 animais de cada grupo genético foram abatidos e suas carcaças avaliadas, de acordo com o Método Brasileiro de Classificação de Carcaça. Não foi observado efeito $(\mathrm{P}>0,05)$ dos níveis de lisina sobre o NUP para os grupos genéticos. Para suínos do GGM em fase de terminação (53 a $92 \mathrm{~kg}$ de PV), a exigência de lisina total é superior a 1,05\%, enquanto, para o GGC (50 a $90 \mathrm{~kg}$ de PV), é de $0,60 \%$ de lisina total.
\end{abstract}

Palavras-chave: aminoácido, características de carcaça, lisina, nitrogênio da uréia plasmática, proteína ideal, suínos em terminação.

\section{Lysine Requirement for Castrated Males of Two Genetic Groups of Swine During Finishing Phase, Based on the Ideal Protein Concept}

\begin{abstract}
A trial was carried out to determine lysine requirements for castrated males during finishing phase of two genetic swine groups, based on the ideal protein concept. Sixteen animals from genetic common group (GCG) were used and another sixteen, from the genetic improved group (GIG) were allotted to four treatments. The treatment consisted on a basal diets, based on corn and soybean meal containing $0.60 \%$ of lysine and other three diet, adding increasing lysine levels to achieve $0.75,0.90$ and $1.05 \%$ of total lysine. Synthetic amino acids were added (L-lysine HCl, DL-methionine, L-threonine and L-tryptophan) to keep amino acid levels according to the ideal protein profile. The plasma urea nitrogen (PUN) concentrations were recorded. The carcass traits were done with in vivo pigs using the Sono Grader ultra sound equipment. At the end of the experimental period, 12 animals were slaughtered and their carcasses were evaluated according to the Brazilian Method of Carcass Classification. It was observed no effect of lysine levels (LL) on PUN for different genetic groups. Lysine requirement for GIG pigs, during finishing phase ( 53 to $92 \mathrm{~kg}$ of live weight), is over $1.05 \%$, whereas for GCG (50 to $90 \mathrm{~kg}$ of live weight) is $0.60 \%$ of total lysine.
\end{abstract}

Key Words: amino acid, carcass traits, finishing swine, ideal protein, lysine, plasma urea nitrogen

\section{Introdução}

A suinocultura é uma atividade amplamente difundida no sul e em vários estados do Brasil, obtendo índices de produtividade que não ficam aquém dos americanos e europeus.

$\mathrm{Na}$ atual situação econômica, para aumentar o lucro, a melhor alternativa é diminuir o custo de produção, sem prejudicar a produtividade. Dentre os custos variáveis da suinocultura, o mais importante é a alimen- tação, portanto, é oportuno desenvolver pesquisas que buscam mecanismos de redução no custo nutricional.

Tem sido abordada uma nova concepção na estratégia de alimentação com o advento dos problemas ambientais, relacionado com a poluição do nitrogênio (N) e amônia $\left(\mathrm{NH}_{3}\right)$ do esterco animal. Os nutricionistas têm como objetivo ajustar as exigências dos suínos, para maximizar a performance de produção no que concerne em evitar o excesso de proteínas e aminoácidos. Este problema não está relacionado

1 Parte da dissertação de mestrado do segundo autor, parcialmente financiado pelo CNPq e pela Ajinomoto.

2 Professor do Departamento de Zootecnia - Universidade Estadual de Maringá, Av. Colombo, 5790 - CEP:87020-900 - Maringá, PR. E.mail: imoreira@uem.br; acfurlan@uem.br

3 Aluno do curso de Mestrado em Zootecnia da UEM.

4 Aluno do curso de Zootecnia, bolsistas de Iniciação Científica, respectivamente, do PIBIB/CNPq e PET/CAPES. 
somente com o $\mathrm{N}$ retido na produção, mas, também, em termos da fração de $\mathrm{N}$ não utilizado do $\mathrm{N}$ ingerido. Sendo assim, o perfeito manejo de alimentação protéica, de acordo com as necessidades dos suínos, é fechar o ajuste proteína/aminoácido para suprir a exigência e

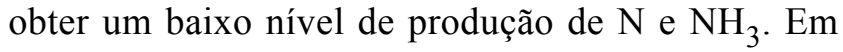
dietas práticas, a lisina é o primeiro aminoácido limitante, sucedido por metionina e treonina. Portanto, a suplementação de lisina, metionina e treonina proporciona um meio para aumentar a eficiência da utilização da proteína e resulta em diminição na excreção de N e $\mathrm{NH}_{3}$ (Shutte, 1997).

Dessa forma, tem-se formulado o conceito de proteína ideal, que pode ser definida como a proteína da dieta com todos os aminoácidos essenciais e a soma dos não essenciais, que são igualmente limitantes (Wang \& Fuller, 1989), objetivando fornecer uma dieta com um perfil de aminoácidos essenciais em relações adequadas para cada função, tendo como base a lisina (ARC, 1981).

Como no conceito de proteína ideal, deve-se determinar as proporções ideais entre diversos aminoácidos e, conhecendo-se a exigência de um aminoácido referencial, pode-se determinar o teor dos outros na dieta.

Um importante benefício do conceito de proteína ideal é que, após estabelecer a exigência para um aminoácido, pode-se determinar a exigência para todos os demais e para o total de proteína bruta da dieta (Tuitoek et al., 1997). O conceito também visa reduzir o excesso de aminoácidos que ocorre em rações protéicas de suínos, sem afetar o desempenho dos animais.

A exigência de aminoácido na dieta para a deposição de proteína no animal se comporta como uma função quadrática, conforme aumenta o peso metabólico $\left(\mathrm{kg}^{0,75}\right)$, contudo, a exigência de aminoácidos para mantença, em contraste, responde linearmente ao aumento do peso metabólico (Hahn \& Baker, 1995). Dessa forma, a exigência de aminoácidos para mantença, de animais em terminação é maior que para animais em crescimento. Portanto, o perfil de aminoácidos varia nas diferentes etapas da vida do suíno.

Trabalhando com marrãs puras da raça Landrace, Donzele et al. (1994) concluíram que marrãs, na fase de terminação (60 aos $100 \mathrm{~kg}$ ), exigem $0,83 \%$ de lisina na dieta.

Segundo dados obtidos em literatura, Ferreira et al. (1996) concluíram que suínos de 60 a $100 \mathrm{~kg}$ exigem $0,75 \%$ de lisina. No entanto, em trabalho de compilação de dados nutricionais de dez empresas que atuam no mercado brasileiro, Benati (1996) encontrou, como média nas rações de terminação, adição prática de $0,78 \%$ de lisina total. O NRC (1998), em sua mais recente publicação, informou a exigência de lisina para suínos de 50 a 80 e 80 a 120 kg como sendo de 0,75 e $0,60 \%$, respectivamente.

O objetivo deste trabalho foi determinar a exigência de lisina de dois diferentes grupos genéticos de suínos, na fase de terminação, com base no conceito de proteína ideal.

\section{Material e Métodos}

O experimento foi conduzido no período de 24 de junho a 05 de agosto de 1998, sendo que as médias de temperatura mínima e máxima foram de 14,24 e $26,48^{\circ} \mathrm{C}$, respectivamente. Os animais foram alojados em um galpão de alvenaria, coberto com telhas de fibrocimento, dividido em duas alas, sendo as mesmas divididas em oito baias $\left(7,60 \mathrm{~m}^{2}\right.$ cada), separadas por um corredor central. Cada baia possuía um comedouro semi-automático de duas bocas, localizado na parte frontal e dois bebedouros do tipo chupeta, no fundo da baia.

Foram utilizados 32 suínos, de dois grupos genéticos diferentes, sendo 16 machos castrados (Landrace $\mathrm{x}$ Large White $\mathrm{x}$ Duroc), com peso médio inicial de $50,4 \pm 1,61 \mathrm{~kg}$, e 16 machos castrados, de elevada produção de carne magra (Agroceres PIC C15 x Ag 400 e C15 x Ag 405), com peso médio inicial de 53,4 2 2,16 kg, denominados, respectivamente, de grupo genético comum (GGC) e grupo genético melhorado (GGM).

O delineamento experimental utilizado foi o de blocos ao acaso, em esquema fatorial $4 \times 2$ (quatro níveis de lisina e dois grupos genéticos), com duas repetições. A unidade experimental foi composta de dois animais por baia. O parentesco e o peso inicial dos leitões foram considerados para a formação das unidades experimentais.

Os tratamentos consistiram de uma ração referência (Tabela 1), à base de milho e farelo de soja, contendo $0,60 \%$ de lisina total e outras três rações, nas quais foram adicionados aminoácidos sintéticos (L-lisina $\mathrm{HCl}$, DL-metionina, L-treonina e L-triptofano), para manter os níveis crescentes de aminoácidos $(0,75 ; 0,90 ;$ e $1,05 \%$ de lisina $)$, de acordo com o perfil de proteína ideal indicado por Baker (1996) para suínos dos 50 aos $110 \mathrm{~kg}$. Da mesma forma, os demais aminoácidos sintéticos foram adicionados para manter constante a relação aminoácido/ lisina. A adição dos aminoácidos foi em substituição ao 
amido do milho. A composição centesimal, química e energética das rações experimentais utilizadas estão nas Tabelas 1 e 2.

As análises de proteína bruta $(\mathrm{PB})$, cálcio $(\mathrm{Ca})$ e fósforo $(\mathrm{P})$ das dietas (Tabela 2 ) foram realizadas de acordo com as metodologias descritas por Silva (1990).

Foram fornecidas água e ração farelada à vontade, durante todo o período experimental. Foram realizadas as pesagens dos animais e consumo de ração, aos 14, 28 e 42 dias de avaliação, após o inicio do período experimental.

As coletas do sangue foram realizadas, após as pesagens dos animais, sem jejum, seguindo indicação de Cai et al. (1994). Foi feita punção na veia cava cranial, retirou-se em torno de $10 \mathrm{ml}$ de sangue, que foi armazenado em tubo de ensaio, devidamente identificado e mantido em gelo até o processamento em laboratório. Aí foi realizada a centrifugação a $3.000 \mathrm{rpm}$, durante 15 minutos para a obtenção do plasma que foi devidamente identificado e mantido armazenado à temperatura de $-20^{\circ} \mathrm{C}$.

Na determinação das concentrações de nitrogênio da uréia plasmática (NUP), foi utilizado o processo enzimático (Kit comercial).

Após a pesagem, aos 42 dias de experimento, realizaram-se as medições das características de carcaça in vivo, utilizando-se um aparelho de ultrasom (RENCOâ Sono Grader), em que a espessura de toucinho (ET) foi o resultado médio das medidas de espessura de toucinho na altura da primeira costela, espessura de toucinho na altura da última costela e espessura de toucinho na altura da última vértebra lombar. A profundidade de lombo (PL) foi obtida na altura da última costela.

Ao final do período experimental, 24 animais, 12 de cada grupo genético, foram abatidos e suas carcaças avaliadas de acordo com o Método Brasileiro de Classificação de Carcaça (ABCS, 1973).

As variáveis estudadas foram submetidas à análise de variância, de acordo com o modelo estatístico:

$$
\mathrm{Y}_{\mathrm{ijk}}=\mu+\mathrm{N}_{\mathrm{i}}+\mathrm{G}_{\mathrm{j}}+\mathrm{B}_{\mathrm{k}}+\mathrm{e}_{\mathrm{ijk}}
$$

em que: $\mathrm{Y}_{i j k}=$ variáveis estudadas. $\mu=$ constante geral; $\mathrm{N}_{\mathrm{i}}=$ efeito do nível de lisina $i$, sendo $(i=0,60$; $0,75 ; 0,90 ;$ e $1,05 \%) ; \mathrm{G}_{\mathrm{j}}=$ efeito do grupo genético $j$ ( $1=$ comum, $2=$ melhorado); $\mathrm{B}_{\mathrm{k}}=$ efeito do bloco $k(k=1$ e 2); e $e_{i j k}=$ erro aleatório associado a cada observação.

Os graus de liberdade referentes a níveis de lisina nas dietas foram desdobrados em polinômios.

Para as variáveis que apresentaram efeito quadrático, foram feitas as derivações das equações, de acordo com o modelo quadrático, para obtenção do melhor nível de lisina.

Tabela 1 - Composição percentual, das dietas fornecidas aos suínos, na fase de terminação, contendo níveis crescentes de lisina

Table 1 - Composition of diets containing increasing lysine levels, fed to finishing pigs

\begin{tabular}{|c|c|c|c|c|}
\hline \multirow[t]{2}{*}{$\begin{array}{l}\text { Ingredientes, } \% \\
\text { Ingredients }\end{array}$} & \multicolumn{4}{|c|}{$\begin{array}{c}\text { Níveis de lisina } \% \\
\text { Lysine levels }\end{array}$} \\
\hline & 0,60 & 0,75 & 0,90 & 1,05 \\
\hline Farelo de soja (Soybean meal) & 8,429 & 8,429 & 8,429 & 8,429 \\
\hline Milho (Corn) & 86,037 & 86,037 & 86,037 & 86,037 \\
\hline Amido de milho (Corn starch) & 2,000 & 1,573 & 1,147 & 0,719 \\
\hline Fosfato bicálcico (Dicalcium phosphate) & 1,542 & 1,542 & 1,542 & 1,542 \\
\hline Calcário (Limestone) & 0,881 & 0,881 & 0,881 & 0,881 \\
\hline Sal comum (Common salt) & 0,400 & 0,400 & 0,400 & 0,400 \\
\hline Tylan-40 (Tylan-40) & 0,023 & 0,023 & 0,023 & 0,023 \\
\hline Suplemento vitamínico ${ }^{\mathrm{a}}$ (Vitamin mix) & 0,200 & 0,200 & 0,200 & 0,200 \\
\hline Suplemento mineral $^{\mathrm{b}}$ (Mineral mix ${ }^{b}$ ) & 0,200 & 0,200 & 0,200 & 0,200 \\
\hline DL-metionina (99,0\%) (Methionine, 99.0\%) & 0,015 & 0,114 & 0,212 & 0,311 \\
\hline L-lisina $\mathrm{HCl}(98,5 \%)($ L-Lysine, $98.5 \%)$ & 0,218 & 0,410 & 0,603 & 0,795 \\
\hline L-treonina $(98,5 \%)$ (L-Threonine, 98.5\%) & 0,054 & 0,161 & 0,268 & 0,375 \\
\hline L-triptofano $(98,5 \%)$ (L-Tryptophan, 98.5\%) & 0,000 & 0,030 & 0,058 & 0,088 \\
\hline
\end{tabular}

a Suplemento vitamínico. Composição por kg da dieta: (Vitamin mix to provide per kg of diet:) Ác. fólico (Folic acid) - 0,334 mg; Vit. A - 4.660 UI; B.H.T. - 65,4 mg; Selênio (Selenium) - 0,1334 mg; Avoparcin (Avoparcin) - 6,68 mg; Colina (Choline) - 86,6 mg; Ác. pantotênico (Pantothenic acid) - 5,334

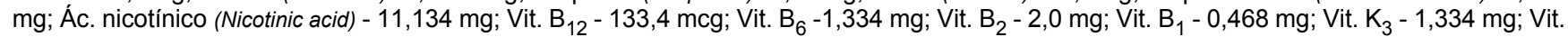
E - 10 UI; Vit. $D_{3}-1.666$ UI; Biotina (Biotine) - 0,05 mg.

b Suplemento mineral. Composição por kg do produto: (Mineral mix to provide per kg of premix:) Co - 1 mg; Cu - 175 mg; Zn - 100 mg; Fe - 100 mg; $\mathrm{Mn}$ - $40 \mathrm{mg} ; \mathrm{l}-1,5 \mathrm{mg}$. 
Tabela 2 - Composições química e energética das dietas fornecidas aos suínos, na fase de terminação, contendo níveis crescentes de lisina

Table 2 - Chemical and energy composition of diets containing increasing lysine levels, fed to finishing pigs

\begin{tabular}{|c|c|c|c|c|}
\hline \multirow[t]{2}{*}{$\begin{array}{l}\text { Ingredientes, } \% \\
\text { Ingredients }\end{array}$} & \multicolumn{4}{|c|}{$\begin{array}{c}\text { Níveis de lisina } \% \\
\text { Lysine levels }\end{array}$} \\
\hline & 0,60 & 0,75 & 0,90 & 1,05 \\
\hline \multicolumn{5}{|l|}{ Valores calculados $^{1}$ (Calculated values) ${ }^{1}$} \\
\hline Proteína bruta (Crude protein), \% & 11,32 & 11,51 & 11,69 & 11,87 \\
\hline Energia digestível (Digestible energy), $\mathrm{kcal} / \mathrm{kg}$ & 3350 & 3353 & 3357 & 3361 \\
\hline Cálcio (Calcium\%), \% & 0,75 & 0,75 & 0,75 & 0,75 \\
\hline Fósforo total (Total phosphorus), \% & 0,56 & 0,56 & 0,56 & 0,56 \\
\hline Lisina (Lysine), $\%$ & 0,60 & 0,75 & 0,90 & 1,05 \\
\hline Metionina + Cistina (Methionine + cystine), $\%$ & 0,39 & 0,49 & 0,59 & 0,68 \\
\hline Treonina (Threonine), \% & 0,42 & 0,53 & 0,63 & 0,74 \\
\hline Triptofano (Tryptophan), \% & 0,11 & 0,14 & 0,17 & 0,20 \\
\hline \multicolumn{5}{|l|}{ Valores analisados (Analyzed values) } \\
\hline Proteína bruta (Crude protein), \% & 11,21 & 11,58 & 11,90 & 12,03 \\
\hline Cálcio (Calcium), \% & 0,66 & 0,66 & 0,64 & 0,64 \\
\hline Fósforo total (Total phosphorus), \% & 0,44 & 0,42 & 0,42 & 0,43 \\
\hline
\end{tabular}

\section{Resultados e Discussão}

Na Tabela 3, encontra-se a composição em aminoácidos, resultado da análise laboratorial das dietas experimentais.

Os resultados de consumo de ração diário (CRD), ganho de peso diário (GPD) conversão alimentar (CA) e consumo de lisina (CL), em função dos níveis de lisina nos períodos 0-14, 0-28 e 0-42 dias de avaliação na fase de terminação, nos dois grupos genéticos, são apresentados na Tabela 4.

Para os animais do grupo genético comum, as variáveis $\mathrm{CRD}$, GPD e CA não sofreram efeito $(\mathrm{P}>0,05)$ dos níveis de lisina, em qualquer dos períodos experimentais.

Os níveis de lisina não exerceram efeito $(\mathrm{P}>0,05)$ sobre o CRD para o grupo genético melhorado, nos períodos de 0-14, 0-28 e 0-42 dias de avaliação. Os resultados encontrados para CRD, em todos os períodos experimentais, tanto para os animais do grupo genético comum, quanto para o melhorado, são semelhantes aos resultados obtidos por Souza et al. (1999), utilizando seis níveis de lisina em suínos mestiços castrados, que não encontraram efeito dos níveis de lisina sobre o consumo de ração.

No grupo genético melhorado, nos períodos de 0-14, 0-28 e 0-42 dias de avaliação, o GPD elevou-se de forma linear $(\mathrm{P}<0,05)$ com o aumento dos níveis de lisina, de acordo com as equações $\mathrm{Y}=0,4827+$ $0,6093 X\left(R^{2}=0,98\right), Y=0,6459+0,4206 X\left(R^{2}=0,94\right)$
$\mathrm{Y}=0,6672+0,2784 \mathrm{X}\left(\mathrm{R}^{2}=0,94\right)$, respectivamente. Estes resultados, são semelhantes aos obtidos por Hansen \& Lewis (1993) que encontraram um comportamento linear do GPD, em função dos níveis de lisina da dieta. Já Willians et al. (1984) observaram comportamento quadrático do GPD, em função dos níveis de lisina $(0,48$ a 0,88\%), em suínos inteiros dos 55 aos $100 \mathrm{~kg}$, com máximo de ganho para $0,78 \%$ de lisina na ração. Friesen et al. (1994), trabalhando com suínos de alto e médio ganho muscular, com peso vivo de 44 a $104 \mathrm{~kg}$, e níveis de lisina de 0,70 ou $0,90 \%$, concluíram que, com o nível mais alto, os animais de alto ganho muscular aumentaram o ganho diário e a eficiência alimentar, comparados com o grupo de médio ganho muscular. Entretanto, Donzele et al. (1998) não encontraram efeito dos níveis de lisina $(0,63 ; 0,73 ; 0,83 ; 0,93$; e $1,03 \%$ ) sobre o GPD em suínos machos inteiros dos 60 aos $100 \mathrm{~kg}$. Souza et al. (1999) também não obtiveram efeito dos níveis de lisina sobre GPD.

Não houve efeito $(\mathrm{P}>0,05)$ dos níveis de lisina sobre a CA para o grupo genético melhorado, nos períodos de 0-14, 0-28 e 0-42 dias de avaliação, diferindo dos resultados encontrados por Donzele et al. (1998), os quais verificaram comportamento quadrático da CA que reduziu até o nível de $0,86 \%$ de lisina para suínos inteiros de 60 a $100 \mathrm{~kg}$ de peso vivo. Segundo Souza et al. (1999), a mesma variável apresentou comportamento quadrático, concluindo que $o$ nível de lisina para machos castrados mestiços, de 60 a $95 \mathrm{~kg}$ de peso vivo é de $0,72 \%$. 
Tabela 3 - Composição em aminoácidos das dietas fornecidas aos suínos, na fase de terminação (valores na matéria natural) ${ }^{1}$ Table 3 - Amino acids composition of diets containing increasing lysine levels, fed to finishing pigs (as-fed basis) 1

\begin{tabular}{|c|c|c|c|c|}
\hline \multirow[t]{2}{*}{$\begin{array}{l}\text { Aminoácidos } \\
\text { Amino acids }\end{array}$} & \multicolumn{4}{|c|}{$\begin{array}{l}\text { Níveis de lisina } \% \\
\text { Lysine levels }\end{array}$} \\
\hline & 0,60 & 0,75 & 0,90 & 1,05 \\
\hline \multicolumn{5}{|l|}{ Essenciais (Essential), \% } \\
\hline Arginina (Arginine) & 0,80 & 0,70 & 0,75 & 0,72 \\
\hline Histidina (Histidine) & 0,38 & 0,34 & 0,35 & 0,34 \\
\hline Isoleucina (Isoleucine) & 0,52 & 0,49 & 0,51 & 0,50 \\
\hline Leucina (Leucine) & 1,29 & 1,30 & 1,27 & 1,26 \\
\hline Lisina (Lysine) & 0,65 & 0,73 & 1,00 & 1,14 \\
\hline Metionina (Methionine) & 0,31 & 0,35 & 0,45 & 0,51 \\
\hline Fenilalanina (Phenylalanine) & 0,65 & 0,63 & 0,64 & 0,62 \\
\hline Treonina (Threonine) & 0,59 & 0,60 & 0,74 & 0,82 \\
\hline Triptofano (Tryptophan) & 0,106 & 0,136 & 0,158 & 0,183 \\
\hline Valina (Valine) & 0,56 & 0,55 & 0,55 & 0,56 \\
\hline \multicolumn{5}{|l|}{ Não Essenciais (Nonessential) } \\
\hline Alanina (Alanine) & 0,79 & 0,78 & 0,75 & 0,76 \\
\hline Ácido aspártico (Aspartic acid) & 1,23 & 1,11 & 1,15 & 1,11 \\
\hline Ácido glutâmico (Glutamic acid) & 2,44 & 2,32 & 2,33 & 2,30 \\
\hline Cistina (Cystine) & 0,25 & 0,24 & 0,23 & 0,23 \\
\hline Glicina (Glycine) & 0,56 & 0,51 & 0,53 & 0,52 \\
\hline Serina (Serine) & 0,66 & 0,62 & 0,63 & 0,62 \\
\hline Tirosina (Tyrosine) & 0,35 & 0,34 & 0,36 & 0,36 \\
\hline
\end{tabular}

1 Análises realizadas na Ajinomoto - Biolatina Indústria e Comércio Ltda.

1 Analyzed by Ajinomoto - Biolatina Indústria e Comércio Ltda..

De acordo com o NRC (1988), suínos com peso vivo entre 50 a $110 \mathrm{~kg}$, alimentados com farelo de soja e milho, requerem $0,60 \%$ de lisina na dieta. Cromwell et al. (1993), trabalhando com suínos machos castrados, com peso vivo entre 51,2 e $105 \mathrm{~kg}$, alimentados com dieta contendo 0,$60 ; 0,75$ e $0,90 \%$ de lisina, observaram melhores resultados ao nível de $0,60 \%$. Já Ferreira et al. (1996) constataram variação de 0,68 a $0,86 \%$ nos valores de exigência de lisina total para suínos de 60 a $100 \mathrm{~kg}$ de peso, enquanto Benati (1996) encontrou valores entre 0,66 e $0,85 \%$ de lisina total, utilizados em rações comerciais, em trabalho de compilação de dados de dez empresas brasileiras.

$\mathrm{Na}$ Tabela 5, encontram-se os resultados da concentração do nitrogênio da uréia plasmático (NUP), nos períodos de 14, 28 e 42 dias de avaliação na fase de terminação, em função dos níveis de lisina na ração para os dois grupos genéticos.

Não foi observado efeito $(\mathrm{P}>0,05)$ dos níveis de lisina sobre o NUP, nos animais dos diferentes grupos genéticos, em nenhum dos períodos experimentais. Estes resultados diferem dos obtidos por Loughmiller et al. (1998), que, trabalhando com marrãs de alto potencial genético (PIC L326 X C 22), com peso vivo de 91 a $113 \mathrm{~kg}$, em dois experimentos, alimentados com dietas em que os níveis de lisina variaram de 0,40 a $0,70 \%$ e 0,60 a $0,90 \%$, verificaram efeito linear $(\mathrm{P}<0,01)$ dos níveis de lisina sobre o NUP, aos $113 \mathrm{~kg}$ de peso vivo.

Houve efeito de grupo genético para o CRD no período de 0-28 e 0-42 dias de avaliação, sendo que, nos dois períodos, o grupo genético melhorado apresentou menor consumo de ração. Não houve efeito $(\mathrm{P}>0,05)$ de grupo genético sobre o NUP.

Os valores médios de espessura de toucinho (ET), profundidade de lombo (PL), rendimento de carcaça (RC), comprimento de carcaça (CC), espessura de toucinho da carcaça fria (ETCF), RP, área de olho de lombo (AOL) e relação carne:gordura $(\mathrm{C} / \mathrm{G})$ ao final do experimento, em função dos níveis de lisina, nos diferentes grupos genéticos encontram-se na Tabela 6 .

O grupo genético melhorado apresentou maior rendimento de pernil $(\mathrm{P}=0,010)$.

No grupo genético comum, observou-se efeito quadrático $(\mathrm{P}<0,05)$, dos níveis de lisina sobre o RP e CC, de acordo com as equações $\mathrm{Y}=47,629046$ $42,380415 X+25,08697 X^{2}\left(R^{2}=0,34\right), Y=62,66887+$ $94,06992 X-62,96295 X^{2}\left(R^{2}=0,61\right)$, respectivamente. Para o grupo genético melhorado, observou-se efeito quadrático $(\mathrm{P}<0,05)$ dos níveis de lisina sobre ETCF, de acordo com a equação $Y=-58,625958+223,19616 \mathrm{X}$ $-131,23 \mathrm{X}^{2}\left(\mathrm{R}^{2}=0,44\right)$. 


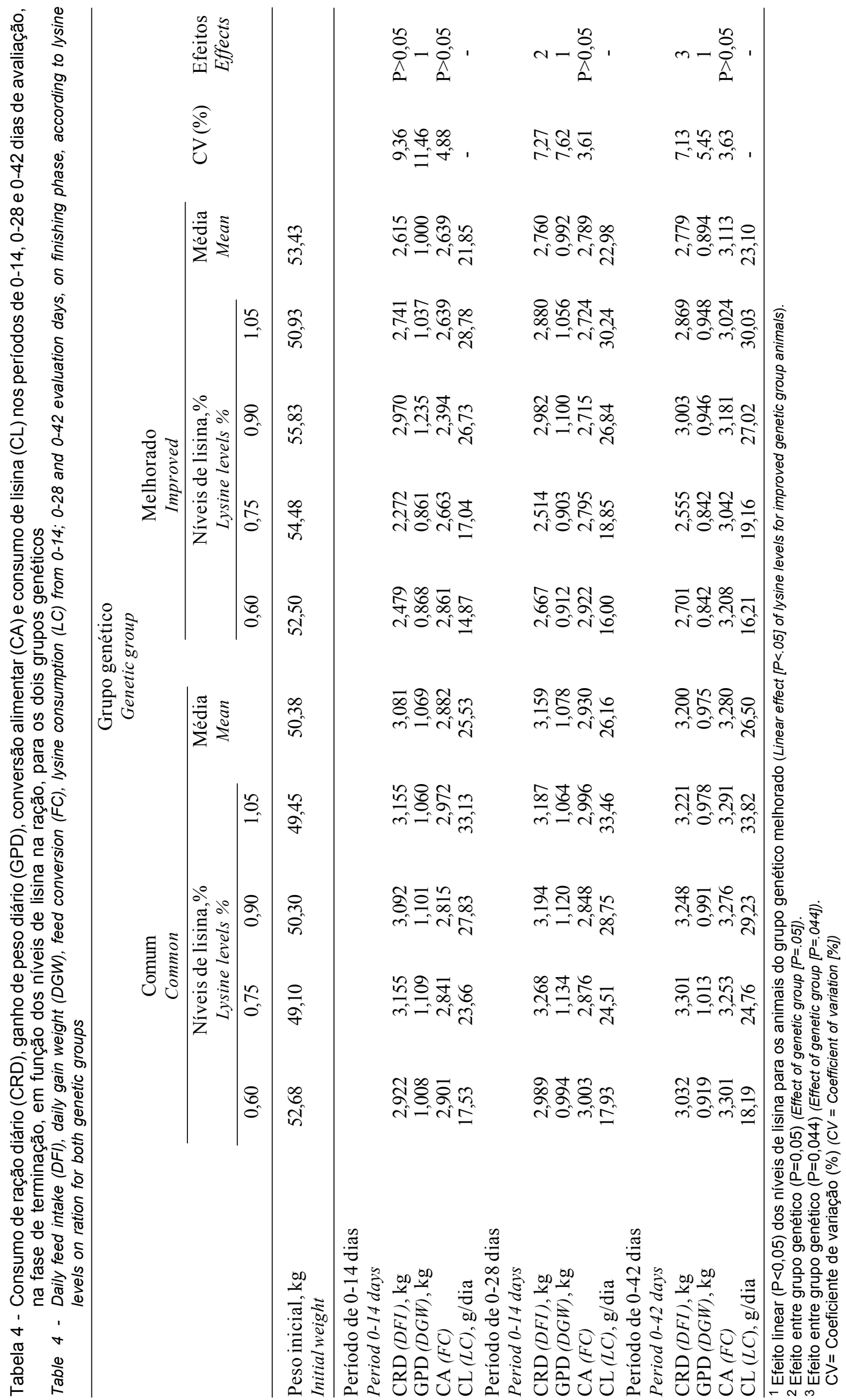




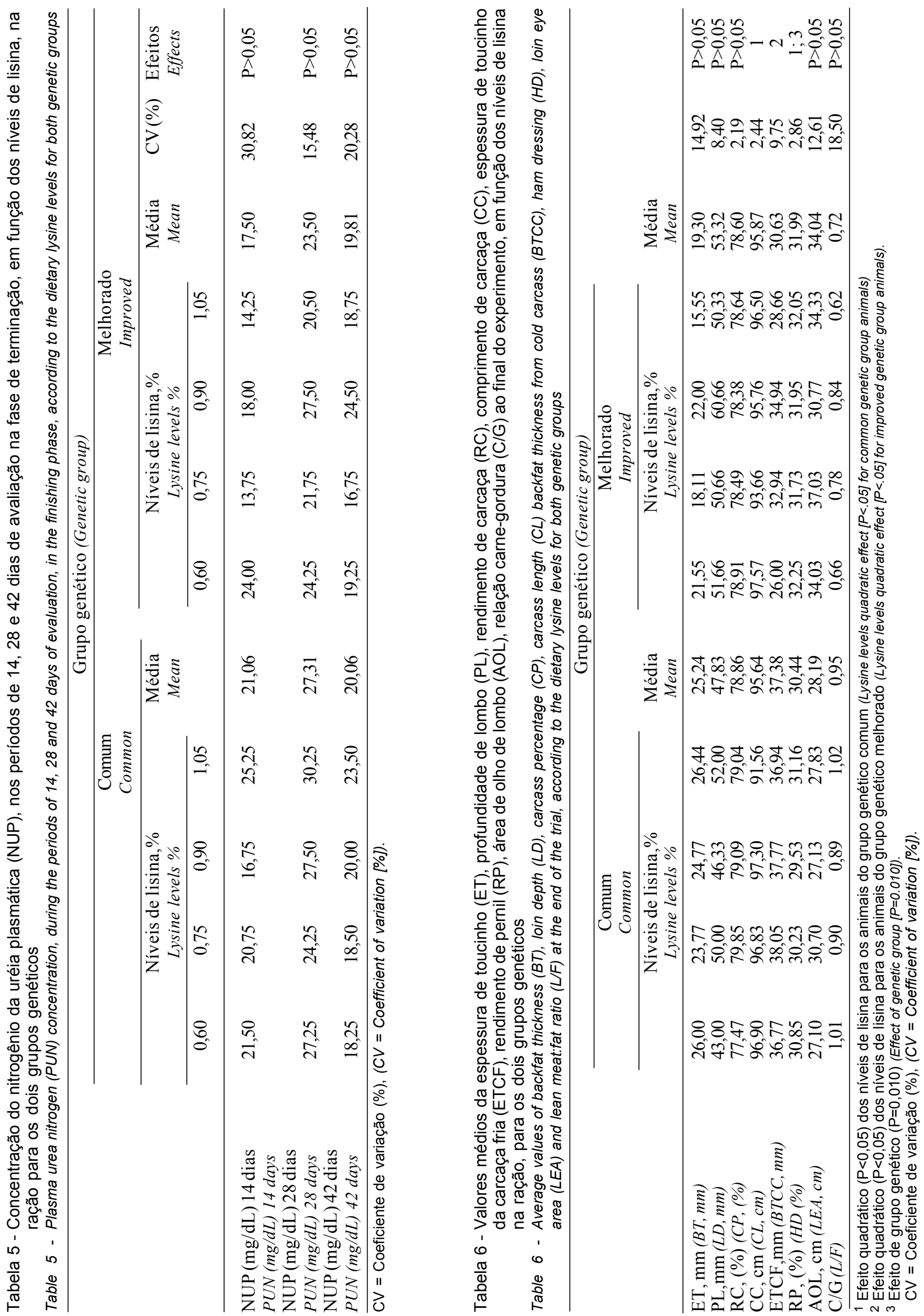


As variáveis ET, PL, RC, AOL e C/G não sofreram efeito dos níveis de lisina da ração. Friesen et al. (1994), trabalhando com genótipos de alto e médio ganho muscular, de 44 a $104 \mathrm{~kg}$ de peso vivo, obtiveram efeito do grupo genético sobre o comprimento da carcaça e não encontraram efeito dos níveis de lisina sobre a espessura de toucinho na décima costela e área do músculo longissimus. Resultados similares foram também encontrados por Cromwell et al. (1993), os quais não obtiveram efeito $(\mathrm{P}>0,05)$ dos níveis de lisina sobre as características de carcaça-(espessura de toucinho e área de olho de lombo) em suínos machos castrados, de 51 a $105 \mathrm{~kg}$ de peso vivo. Da mesma forma, Loughmiller et al. (1998), trabalhando com marrãs com peso vivo de 91 a $113 \mathrm{~kg}$, não verificaram efeito dos níveis de lisina $(0,60 ; 0,70 ; 0,80$ e $0,90 \%)$ sobre a espessura de toucinho e área de olho de lombo.

\section{Conclusões}

Os resultados de desempenho indicam que a exigência de lisina, baseada no conceito de proteína ideal, para suínos do grupo genético melhorado em fase de terminação ( 53 a $92 \mathrm{~kg}$ de PV), é superior a $1,05 \%$, enquanto para o grupo genético comum (50 a $90 \mathrm{~kg}$ de PV) é de $0,60 \%$ de lisina total.

\section{Agradecimento}

Em especial, à AJINOMOTO BIOLATINA Ind. e Comércio Ltda., pelo fornecimento dos aminoácidos, bem como pelas análises de aminoácidos.

\section{Literatura Citada}

ASSOCIAÇÃO BRASILEIRA DE CRIADORES DE SUÍNOS Método Brasileiro de Classificação de Carcaças. Estrela, RS: 1973, 17p. (Publicação Técnica, 2)

AGRICULTURAL RESEARCH COUNCIL - ARC. The nutrient requirements of pigs. Farnham Royal, Slough: Commonwealth Agricultural Bureaux, 1981, 307p.

BAKER, D.H. Advances in amino acid nutrition and metabolism of swine and poultry. In: KORNEGAY, E.T. (Ed.) Nutrient management of food animals to enhance and protect the environment. Boca Raton: CRC - Lewis, 1996. p.41-53.

BENATI, M. Níveis nutricionais utilizados nas dietas de suínos. In: SIMPÓSIO INTERNACIONAL SOBRE EXIGÊNCIAS NUTRICIONAIS DE AVES E SUÍNOS, 1996, Viçosa. Anais... Viçosa, MG: Universidade Federal de Viçosa, 1996. p.447-457.

CAI, Y; ZIMMERMAN, D.R; EWAN, R.C. Diurnal variation in concentrations of plasma urea nitrogen and amino acids in pigs given free access to feed or fed twice daily. Journal of Nutrition, v.124, p.1088-1093, 1994.

CROMWELL, G.J.; CLINE, T.R.; CRENSHAW, J.D. et al. The dietary protein and(or) lysine requirements of barrows and gilt. Journal of Animal Science, v.71, n.6, p.1510-1519, 1993.
DONZELE, J.L.; FREITAS, R.T.F.; OLIVEIRA, R.F.M. et al. Níveis de lisina para marrãs dos 60 aos $100 \mathrm{~kg}$ de peso vivo. Revista da Sociedade Brasileira de Zootecnia, v.23, n.6, p.959-966, 1994.

DONZELE, J.L.; OLIVEIRA, R.F.M.; FONSECA, C.C. Níveis de lisina para suínos machos inteiros dos 60 aos $100 \mathrm{~kg}$. Revista Brasileira de Zootecnia, v.27, n.1, p.117-122, 1998.

EMPRESA BRASILEIRA DE PESQUISA AGROPECUÁRIA EMBRAPA. Centro Nacional de Pesquisa de Suínos e Aves (Concórdia - SC). Tabelas de composição química e valores energéticos de alimentos para suínos e aves. 3.ed. Concórdia: 1991. 97p. (EMBRAPA-CNPSA. Documentos, 19).

FERREIRA, A.S.; PUPA, J.M.R.; SOUZA, A.M. Exigências nutricionais para suínos determinadas no Brasil. In: SIMPÓSIO INTERNACIONAL SOBRE EXIGÊNCIAS NUTRICIONAIS DE AVES E SUÍNOS, 1996, Viçosa. Anais... Viçosa, MG: Universidade Federal de Viçosa, 1996. p.447-547.

FRIESEN K.G.; NELSSEN J.L.; UNRUH J.A. et al. Effects of the interrelationship between genotype, sex, and dietary lysine on growth performance and carcass composition in finishing pigs fed to either 104 or 127 kilograms. Journal of Animal Science, v.72, n.4, p.946-954, 1994.

HAHN, J.D.; BAKER, D.H. Optimum ratio to lysine of threonine, tryptophan, and sulfur amino acids for finishing swine. Journal of Animal Science, v.73, p.2, p.482-489, 1995.

HANSEN, B.C.; LEWIS, A.J. Effects of dietary protein concentration (corn:soybean meal ration) on the performance and carcass characteristics of growing boars, barrows and gilts: mathematical descriptions. Journal of Animal Science, v.71, n.8, p.2122-2132, 1993.

LOUGHMILLER J.A.; NELSSEN, J.L.; GOODBAND R.D. et al. Influence of dietary lysine on growth performance and carcass characteristics of late-finishing gilts. Journal of Animal Science, v.76, n.8, p.1075-1080, 1998.

NATIONAL ACADEMY OF SCIENCE. Nutrient requirements of swine. 9.ed. Washington: 1988. 93p. (Nutrient requirements of domestics animals).

NATIONAL ACADEMY OF SCIENCE. Nutrient requirements of swine. 10.ed. Washington: 1998. 189p. (Nutrient requirements of domestics animals).

RHÔNE-POULENC. Nutrition guide - Feed formulation with digestible amino acids. 1.ed. RHÔNE-P0ULENC Animal Nutrition, Commentry-France. 1989. 35p.

SHUTTE, J.B. Protein and amino acid requirement of pigs. In: RHÔNE-POULENC SYMPOSIUM, 1997, Utrecht. RhônePoulenc... Utrecht: Rhône Poulenc, 1997. p.1-8.

SILVA, D.J. Análise de alimentos: métodos químicos e biológicos. Viçosa, MG: Universidade Federal de Viçosa, 1990. 165p.

SOUZA, A.M.; ROSTAGNO, H.S.; PUPA, J.M.R. et al. Exigências nutricionais de lisina para suínos mestiços, de 60 a $95 \mathrm{~kg}$ de peso. In: REUNIÃO ANUAL DA SOCIEDADE BRASILEIRA DE ZOOTECNIA, 36., 1999, Porto Alegre. Anais... Porto Alegre: Universidade Federal do Rio Grande do Sul, 1999. p.227.

TUITOEK, J.K.; YOUNG, L.G.; LANGE, C.F.M. Composition and protein and fat accretion in various body components in growing gilts fed diets with different protein levels but estimated to contain similar levels of ideal protein. Journal of Animal Science, v.75, n.6, p.1584-1590, 1997.

WANG, T.C.; FULLER, M.F. The optimum dietary amino acid pattern for growing pigs. Experiments by amino acid deletion. Bristh Journal Nutrition, v.62, p.77-89, 1989.

WILLIANS, W.D.; CROMWELL, G.L.; STAHLY, T.S. et al. The lysine requirements of the growing boars versus barrow. Journal of Animal Science, v.58, n.3, p.657-655, 1984.

Recebido em: 12/02/01 Aceito em: 27/08/01 